\title{
Near-monodisperse Ni-Cu Bimetallic Nanocrystals of Variable Composition: Controlled Synthesis and Catalytic Activity for $\mathbf{H}_{2}$ Generation
}

Yawen Zhang, Wenyu Huang, Susan E. Habas, John N. Kuhn, Michael E. Grass, Yusuke Yamada, Peidong Yang, and Gabor A. Somorjai*

Department of Chemistry, University of California, Berkeley, CA 94720, and the Chemical and Materials Sciences Divisions, Lawrence Berkeley National Laboratory, 1 Cyclotron Road, Berkeley, CA 94720. $¥$ College of Chemistry and Molecular Engineering, Peking University, Beijing 100871, China. E-mail: somorjai@ berkeley.edu.

\begin{abstract}
Near-monodisperse $\mathrm{Ni}_{1-x} \mathrm{Cu}_{x}(x=0.2-0.8)$ bimetallic nanocrystals were synthesized by a one-pot thermolysis approach in oleylamine/1-octadecene, using metal acetylacetonates as precursors. The nanocrystals form large-area 2D superlattices, and display a catalytic synergistic effect in the hydrolysis of $\mathrm{NaBH}_{4}$ to generate $\mathrm{H}_{2}$ at $x=0.5$ in a strongly basic medium. The $\mathrm{Ni}_{0.5} \mathrm{Cu}_{0.5}$ nanocrystals show the lowest activation energy, and also exhibit the highest $\mathrm{H}_{2}$ generation rate at $298 \mathrm{~K}$.
\end{abstract}

\section{Graphic abstract}

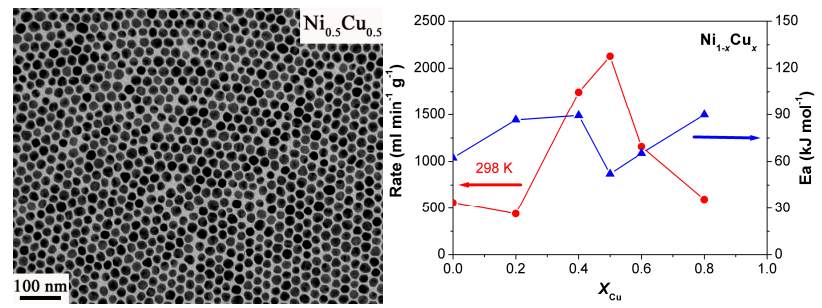




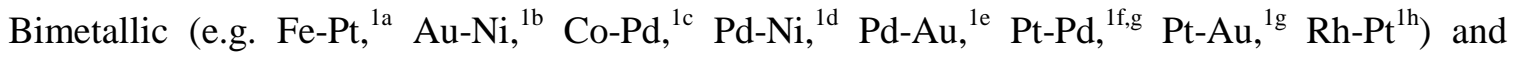
trimetallic (e.g. $\mathrm{Ru}_{5} \mathrm{PtSn}^{1 \mathrm{i}}$ ) nanocrystals $(\mathrm{NCs})$ with tunable chemical and physical properties have attracted extensive theoretical and practical interest. ${ }^{1,2}$ In particular, these NCs usually display composition-dependent surface structure and atomic segregation behavior, so they are important materials for developing new catalysts with enhanced activity and selectivity. ${ }^{1 \mathrm{c}-\mathrm{i}, 2}$ Solution based synthetic approaches such as non-hydrolytic reduction in hot surfactant solutions, ${ }^{1, \mathrm{~d}}$ dendrimer templating ${ }^{1 \mathrm{e}, \mathrm{f}}$, micelle templating ${ }^{1 \mathrm{~g}}$ and polyol reduction ${ }^{\text {lh }}$ have been demonstrated to be versatile and robust methods to control the chemical composition, size and shape of NCs. The selection of proper metal precursors and regulation of the bonding interactions between particle surfaces and capping molecules play crucial roles in obtaining highly monodisperse and compositionally homogeneous NCs.

$\mathrm{Ni}-\mathrm{Cu}$ alloys are efficient catalysts for some important heterogeneous reactions such as methane decomposition, ${ }^{3 \mathrm{a}}$ citral and cinnamaldehyde hydrogenations, ${ }^{3 \mathrm{~b}}$ and electro-catalytic oxidation of methanol. ${ }^{3 c}$ So far, several limited physical and chemical methods have been developed to prepare Ni$\mathrm{Cu}$ nanocrystalline particles. ${ }^{4}$ However, the synthesis of monodisperse, faceted, and phase-pure Ni-Cu nanoscale alloys has still remained a great challenge.

In this Letter, we report the synthesis of near-monodisperse $\mathrm{Ni}_{1-x} \mathrm{Cu}_{x}(x=0.2-0.8) \mathrm{NCs}$ by a onepot thermolysis approach in hot surfactant solutions. The NCs form large-area superlattices and show a catalytic synergistic effect in hydrolysis of $\mathrm{NaBH}_{4}$ to generate $\mathrm{H}_{2}$.

For a typical synthesis (Table $\mathrm{S} 1), 0.1 \mathrm{mmol} \mathrm{Ni(acac})_{2}$ and $0.1 \mathrm{mmol} \mathrm{Cu}(\mathrm{acac})_{2}$ were predissolved in $1 \mathrm{ml}$ of dry oleylamine $(\mathrm{OM})$ at $85{ }^{\circ} \mathrm{C}$ in an oil bath. Dry oleylamine and 1-octadecene (ODE) in a given volume were put into a $50 \mathrm{ml}$ three-necked flask at room temperature. The solvent was heated to $140{ }^{\circ} \mathrm{C}$ in an electromantle and evacuated at this temperature for $20 \mathrm{~min}$ to remove water and oxygen under magnetic stirring. The solvent was then heated to $230{ }^{\circ} \mathrm{C}$ at $10{ }^{\circ} \mathrm{C} \mathrm{min}^{-1}$. The pre-dissolved metal precursors were injected into the heated solvent inside the flask with a plastic syringe in $20 \mathrm{sec}$, and were allowed to further react for $10 \mathrm{~min}$ at this temperature under Ar. When the reaction was complete, an excess of absolute ethanol was added at room temperature to form a cloudy black suspension. This suspension was separated by centrifugation, and the NCs were collected. 

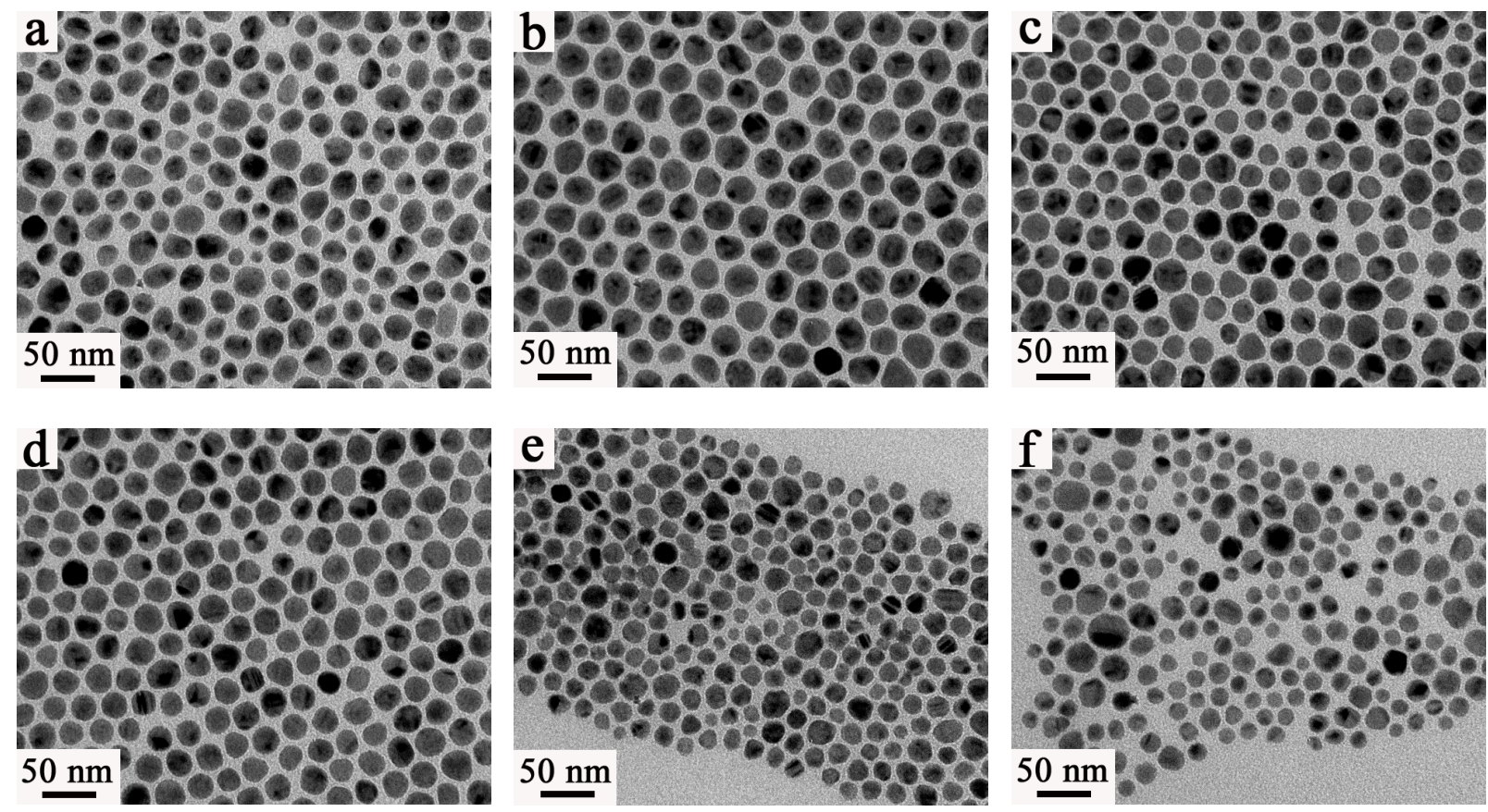

Figure 1. TEM images of $\mathrm{Ni}_{1-x} \mathrm{Cu}_{x}$ NCs: (a) $x=0$; (b) $x=0.2$; (c) $x=0.4$; (d) $x=0.5$; (e) $x=0.6$; (f) $x$ $=0.8$.

Transmission electron microscopy (TEM, Philips FEI Tecnai 12, $100 \mathrm{kV}$ ) showed that $\mathrm{Ni}_{1-x} \mathrm{Cu}_{x}$ NCs formed ordered two dimensional (2D) hexagonal-close-packed (hcp) nanoarrays over large areas, demonstrating their low polydispersity and good surface capping by oleylamine (Figures 1 and S1). The crystallite sizes of $\mathrm{Ni}, \mathrm{Ni}_{0.8} \mathrm{Cu}_{0.2}, \mathrm{Ni}_{0.6} \mathrm{Cu}_{0.4}, \mathrm{Ni}_{0.5} \mathrm{Cu}_{0.5}, \mathrm{Ni}_{0.4} \mathrm{Cu}_{0.6}$, and $\mathrm{Ni}_{0.2} \mathrm{Cu}_{0.8} \mathrm{NCs}$ are $22.3 \pm 3.4$, $27.3 \pm 2.4,23.1 \pm 2.1,22.7 \pm 1.7,17.8 \pm 3.4$, and $19.3 \pm 4.4 \mathrm{~nm}$, respectively. High resolution TEM (HRTEM, Philips CM200/FEG, $200 \mathrm{kV}$ ) revealed that the $\mathrm{Ni}_{1-x} \mathrm{Cu}_{x} \mathrm{NCs}$ are of high crystallinity. The $\mathrm{Ni}_{0.5} \mathrm{Cu}_{0.5} \mathrm{NCs}$ are composed of single-crystalline particles (Figures 2a), and multiple twined particles (MTPs) (Figures 2b), with exposed (111) faces. Energy dispersive X-ray (EDX) analysis of a single $\mathrm{Ni}_{0.5} \mathrm{Cu}_{0.5} \mathrm{NC}$ indicated that the $\mathrm{NCs}$ are 45 at.\% $\mathrm{Ni}$ and 55 at.\% $\mathrm{Cu}$ (Figure 2c), confirming the formation of bimetallic NCs with the nominal composition. X-ray line scan profile along the line indicated in the ADF-STEM image further suggested that the bimetallic NCs are $\mathrm{Cu}$ rich in the core region and Ni rich in the surface region (Figure 2d). X-ray diffraction (XRD, Bruker D8 GADDS, Co$\mathrm{K}_{\square}$ radiation of $\lambda=1.79 \AA$ ) suggested that the as-obtained Ni NCs contains a mix of hexagonal (hcp) 
and face-centered cubic (fcc) phases (Figure 3). As $x$ rose from 0 to 0.05 to 0.1 , the amount of cubic phase in the NCs increased. For $x=0.2-0.8$, the as-obtained $\mathrm{Ni}_{1-x} \mathrm{Cu}_{x} \mathrm{NCs}$ adopt an fcc structure (Figure 3), in agreement with previous reports. ${ }^{4 a, 5}$ The calculated lattice constants were $a=0.3607 \mathrm{~nm}$ for the $\mathrm{Ni}_{0.8} \mathrm{Cu}_{0.2} \mathrm{NCs}, a=0.3609 \mathrm{~nm}$ for the $\mathrm{Ni}_{0.6} \mathrm{Cu}_{0.4} \mathrm{NCs}, a=0.3613 \mathrm{~nm}$ for the $\mathrm{Ni}_{0.5} \mathrm{Cu}_{0.5} \mathrm{NCs}$ (JCPDS: 71-7832), $a=0.3614 \mathrm{~nm}$ for the $\mathrm{Ni}_{0.4} \mathrm{Cu}_{0.6} \mathrm{NCs}$, and $a=0.3616 \mathrm{~nm}$ for the $\mathrm{Ni}_{0.2} \mathrm{Cu}_{0.8} \mathrm{NCs}$.
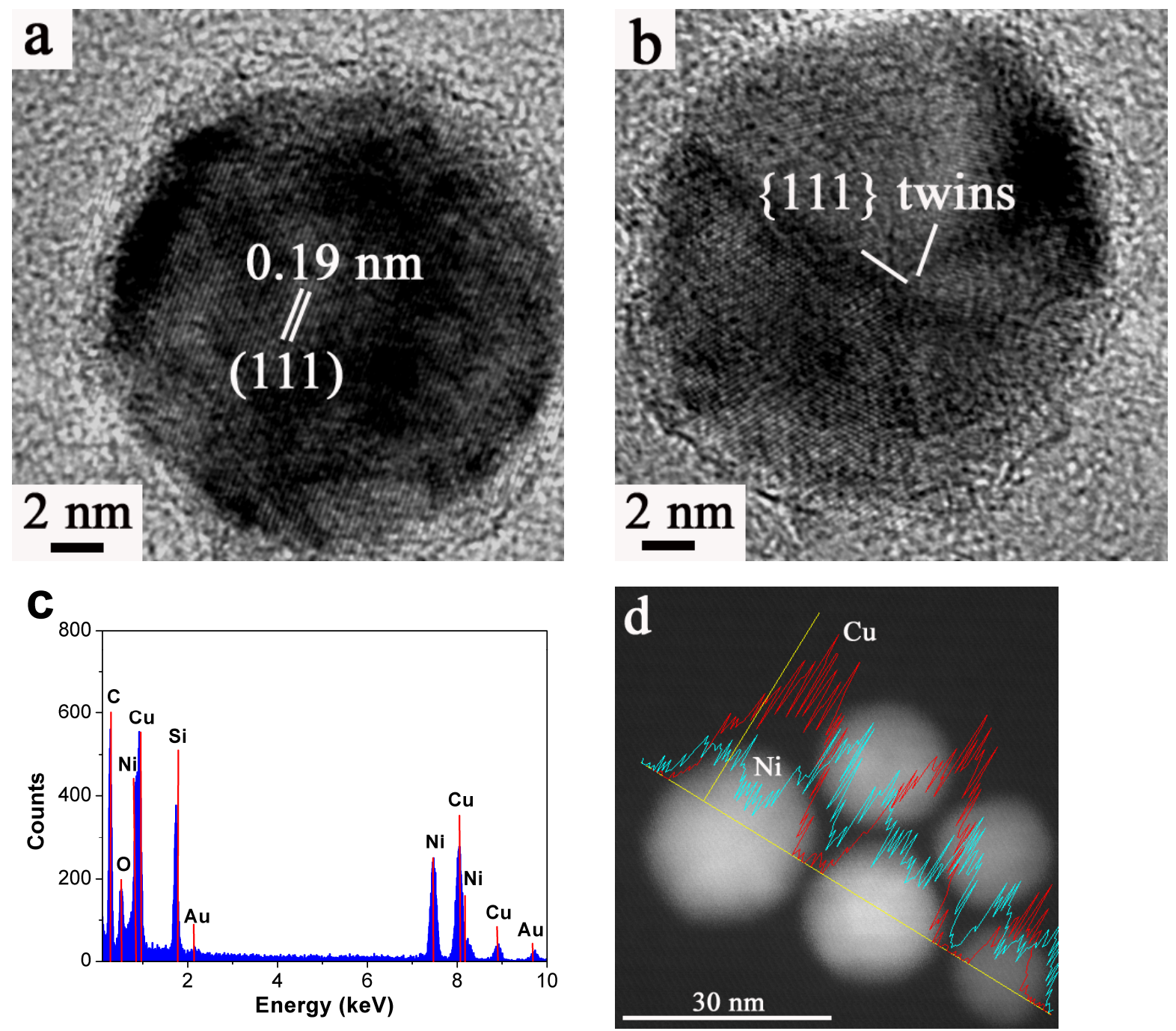

Figure 2. (a and b) HRTEM images of $\mathrm{Ni}_{0.5} \mathrm{Cu}_{0.5} \mathrm{NCs}$. (c) EDX spectrum of a single $\mathrm{Ni}_{0.5} \mathrm{Cu}_{0.5} \mathrm{NC}$ on a Au grid. (d) ADF-STEM image and X-ray line scan profile along the line indicated in this image. 


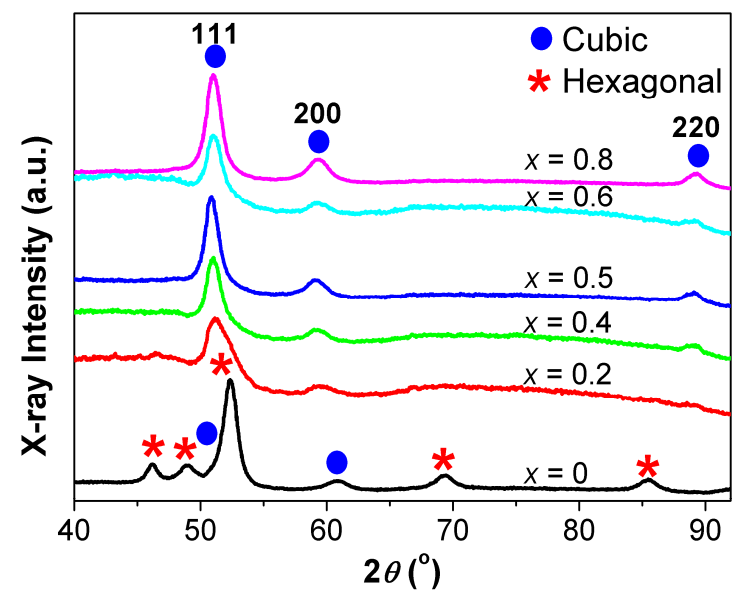

Figure 3. $\mathrm{XRD}$ patterns of $\mathrm{Ni}_{1-x} \mathrm{Cu}_{x} \mathrm{NCs}$.

Optimal conditions for the formation of high-quality $\mathrm{Ni}_{1-x} \mathrm{Cu}_{x} \mathrm{NCs}$ were explored through control experiments. Using $0.1 \mathrm{mmol} \mathrm{Ni}(\mathrm{acac})_{2}$ and $0.1 \mathrm{mmol} \mathrm{Cu}(\mathrm{acac})_{2}$ as precursors, the reaction at $220{ }^{\circ} \mathrm{C}$ in oleylamine produced poorly-crystallized (Figure S2a) polydisperse (Figure S2b) $\mathrm{Ni}_{0.5} \mathrm{Cu}_{0.5} \mathrm{NCs}$; while the reaction at $250{ }^{\circ} \mathrm{C}$ yielded phase-separated (Figure S2a) polydisperse NCs containing very big polygonal and rod-like particles (Figure S2d). Only at temperatures near $230{ }^{\circ} \mathrm{C}$, phase-pure and highly-crystalline (Figure S2a) near-monodisperse $\mathrm{Ni}_{0.5} \mathrm{Cu}_{0.5} \mathrm{NCs}$ were formed $(22.9 \pm 2.5 \mathrm{~nm}$; Figure S2c). At a fixed temperature of $230{ }^{\circ} \mathrm{C}$, the addition of different amounts of ODE into OM improved the monodispersity and permitted size control of the $\mathrm{Ni}_{0.5} \mathrm{Cu}_{0.5} \mathrm{NCs}$. For example, $14.9 \pm 1.5 \mathrm{~nm}$ (Figure S3a), $16.1 \pm 1.4 \mathrm{~nm}$ (Figure S3b) and $22.7 \pm 1.7 \mathrm{~nm}$ (Figure 1d) $\mathrm{Ni}_{0.5} \mathrm{Cu}_{0.5} \mathrm{NCs}$ were obtained at ODE:OM = 0:20, 5:15 and 10:10 (in v/v), respectively. However, as the volume ratio of ODE:OM exceeds 10:10, the $\mathrm{Ni}_{0.5} \mathrm{Cu}_{0.5} \mathrm{NCs}$ grow much bigger and more polydisperse (Figure $\mathrm{S} 3 \mathrm{c}, \mathrm{S} 3 \mathrm{~d}$ ). Therefore, high-quality $\mathrm{Ni}_{1-x} \mathrm{Cu}_{x} \mathrm{NCs}$ were obtained by finely tuning the ODE:OM ratio at $230{ }^{\circ} \mathrm{C}$ (Table S1), due to the delicate control of the solvent's coordinating behavior. ${ }^{1 \mathrm{a}, 6}$

With the Langmuir-Blodgett (LB) technique, ${ }^{7}$ the $\mathrm{Ni}_{1-x} \mathrm{Cu}_{x}$ NCs were deposited onto silicon wafers to form 2D model catalysts after the removal of excess oleylamine ligands by dissolution and precipitation treatment with methanol and hexanes. They were then tested for catalytic hydrolysis of $\mathrm{NBH}_{4}$ to generate $\mathrm{H}_{2}$ in a strongly basic medium $\left(0.16 \mathrm{~g}\right.$ of $\mathrm{NaBH}_{4}$ in $5 \mathrm{ml}$ of $\left.15 \mathrm{wt} . \% \mathrm{NaOH}\right)$ at 298- 
$308 \mathrm{~K}^{8}{ }^{8}$ The $\mathrm{H}_{2}$ generation rates of all nanocatalysts monotonically increased from $298 \mathrm{~K}$ to $308 \mathrm{~K}$ (Figure 4a), and the $\mathrm{Ni}_{1-\mathrm{x}} \mathrm{Cu}_{\mathrm{x}}(x=0.4-0.5) \mathrm{NCs}$ were quite active for this reaction. At $298 \mathrm{~K}$, the $\mathrm{H}_{2}$ generation rates for the NCs are in the range of 439-2127 $\mathrm{ml} \mathrm{min}^{-1} \mathrm{~g}^{-1}$ (Figure 4b), and were comparable to those reported for Ni-Co-B catalysts. ${ }^{8 a}$ The apparent activation energy for hydrolysis by the Ni NCs was $62.3 \mathrm{~kJ} \mathrm{~mol}^{-1}$, lower than that of bulk Ni $\left(71 \mathrm{~kJ} \mathrm{~mol}^{-1}\right),{ }^{8 b}$ but close to that of Raney $\mathrm{Ni}\left(63 \mathrm{~kJ} \mathrm{~mol}^{-1}\right){ }^{8 \mathrm{~b}}$ Activation energies for the $\mathrm{Ni}_{0.8} \mathrm{Cu}_{0.2}, \mathrm{Ni}_{0.6} \mathrm{Cu}_{0.4}, \mathrm{Ni}_{0.5} \mathrm{Cu}_{0.5}, \mathrm{Ni}_{0.4} \mathrm{Cu}_{0.6}$, and $\mathrm{Ni}_{0.2} \mathrm{Cu}_{0.8}$ NCs are 86.6, 89.4, 52.1, 65.3, and $89.9 \mathrm{~kJ} \mathrm{~mol}^{-1}$, respectively. Consequently, among the tested catalysts, $\mathrm{Ni}_{0.5} \mathrm{Cu}_{0.5} \mathrm{NCs}$ show the lowest activation energy, and also exhibit the highest $\mathrm{H}_{2}$ generation rate at $298 \mathrm{~K}$ (Figure 4b), suggesting a catalytic synergistic effect in the hydrolysis of $\mathrm{NaBH}_{4}$ at $x=$ 0.5. This catalytic enhancement is supposed to be caused by the combined turnover from surface $\mathrm{Ni}$ sites and partially dissolved metal ions such as $\mathrm{Ni}^{2+}$ and $\mathrm{Cu}^{2+}$ as the $\mathrm{NC}$ surfaces were exposed to the strong basic solution. ${ }^{8}$ Furthermore, the observed activation energy dependence on the copper content in this work might arise from reaction kinetics changes for various compositions, predominately induced by the complicated surface reactions among surface metal atoms, residual capping species, and deionized $\mathrm{OH}^{-}$ions in the presence of $\mathrm{H}_{2}$ and $\mathrm{NaBO}_{2}{ }^{8}$
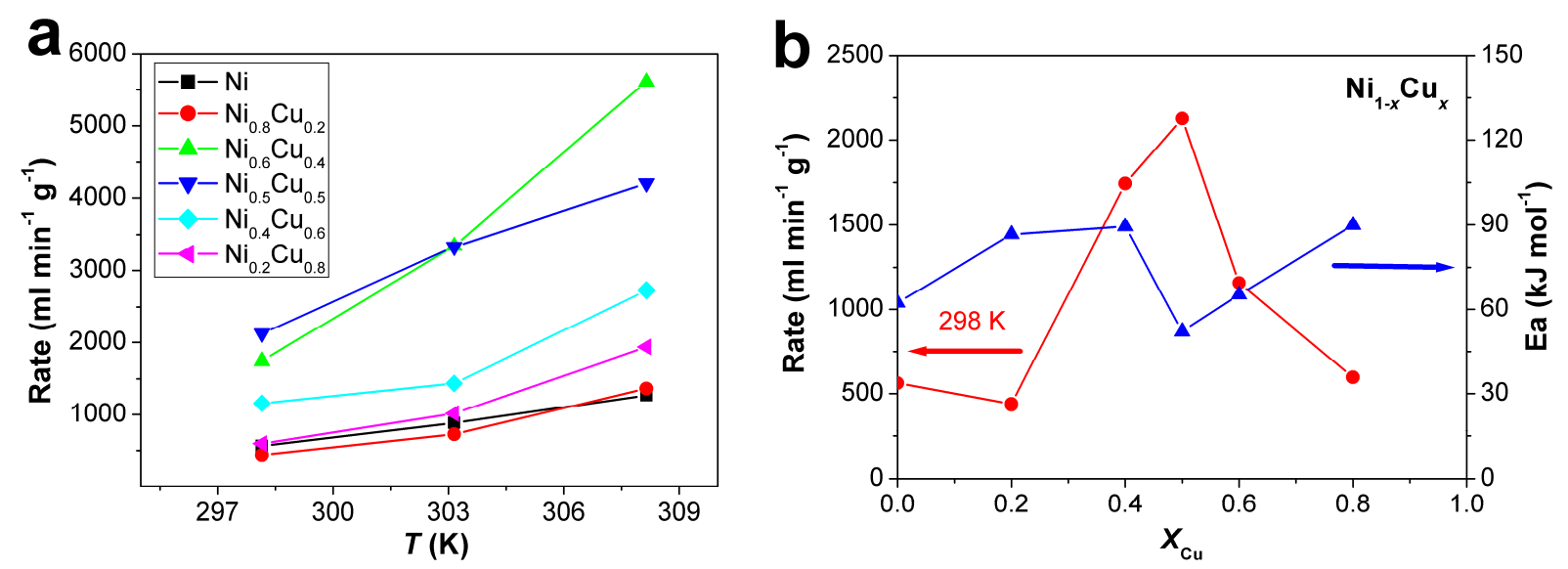

Figure 4. (a) $\mathrm{H}_{2}$ generation rate as a function of absolute temperature $\left(0.16 \mathrm{~g}\right.$ of $\mathrm{NaBH}_{4}$ in $5 \mathrm{ml}$ of 15 wt.\% $\mathrm{NaOH}$ ). (b) $\mathrm{H}_{2}$ generation rate at $298 \mathrm{~K}$ and activation energy as a function of $\mathrm{Cu}$ molar fraction. 
In conclusion, we demonstrated an efficient synthesis of high-quality $\mathrm{Ni}_{1-x} \mathrm{Cu}_{x}(x=0.2-0.8)$ bimetallic NCs by a one-pot thermolysis method in oleylamine/1-octadecene, using metal acetylacetonates as precursors. The NCs form large-area 2D superlattices, and display a catalytic synergistic effect in the hydrolysis of $\mathrm{NaBH}_{4}$ to generate $\mathrm{H}_{2}$ at $x=0.5$ in a strongly basic medium. The $\mathrm{Ni}_{0.5} \mathrm{Cu}_{0.5} \mathrm{NCs}$ show the lowest activation energy, and also exhibit the highest $\mathrm{H}_{2}$ generation rate at $298 \mathrm{~K}$. The Ni-Cu bimetallic NCs may be also used as catalysts in other selective heterogeneous reactions, and the present synthesis has already been applied to many other bimetallic NCs (e.g., Ni$\mathrm{Pd}, \mathrm{Ni}-\mathrm{Rh}$ and Ni-Co).

Acknowledgment. This work was supported by the Director, Office of Science, Office of Basic Energy Sciences, Materials Sciences and Engineering and Chemical Sciences, Geosciences, and Biosciences Divisions, of the U.S. Department of Energy under Contract No. DE-AC02-05CH11231. The authors thank Virginia Altoe at Molecular Foundry of the Lawrence Berkeley National Laboratory for X-ray line scan profile analysis. Y.W.Z. appreciates the financial aid of Huaxin Distinguished Scholar Award from Peking University Education Foundation of China.

Supporting Information Available: More TEM images, XRD results, and detailed experimentation are included in supporting information. This material is available free of charge via the Internet at http://pubs.acs.org.

\section{References}

(1) (a) Sun, S.; Murray, C. B.; Weller, D.; Folks, L.; Moser, A. Science 2000, 287, 1989. (b) Salem, A. K; Searson, P. C.; Leong, K. W. Nature Mater. 2003, 2, 668. (c) Heemeier, M.; Carlsson, A. F.; Naschitzki, M.; Schmal, M.; Bäumer, M.; Freund, H.-J. Angew. Chem. Int. Ed., 2002 41, 4073. (d) Son, S. U.; Jang, Y.; Park, J.; Na, H. B.; Park, H. M.; Yun, H. J.; Lee, J.; Hyeon, T. J. Am. Chem. Soc. 2004, 126, 5026. (e) Scott, R. W. J.; Wilson, O. M.; Oh, S.-K.; Kenik, E. A.; Crooks, R. M. J. Am. Chem. Soc. 2004, 126, 15583. (f) Ye, H.; Crooks, R. M. J. Am. Chem. Soc. 2007, 129, 3627. (g) Habas, S. E.; Lee, H.; Radmilovic, V.; Somorjai, G. A.; Yang, P. Nature Mater. 2007, 6, 692. (h) Park, J. Y.; Zhang, Y.; Grass, M.; Zhang, T.; Somorjai, G. A. Nano Lett., 2008, 8, 
673. (i) Hungria, A. B.; Raja, R.; Adams, R. D.; Captain, B.; Thomas, J. M.; Midgley, P. A.; Golovko, V.; Johnson, B. F. G. Angew. Chem. Int. Ed., 2006, 45, 4782.

(2) (a) Greeley, J.; Mavrikakis, M. Nature Mater. 2004, 3, 810. (b) Fernández, J. L.; Walsh, D. A.; Bard; A. J. J. Am. Chem. Soc. 2005, 127, 357. (c) Ferrando, R.; Jellinek, J.; Johnston, R. L. Chem. Rev. 2008, 108, 845.

(3) (a) Reshetenko, T. V.; Avdeeva, L. B.; Ismagilov, Z. R.; Chuvilin, A. L.; Ushakov, V. A. Appl. Catal. A 2003, 247, 51. (b) Asedegbega-Nieto, E.; Bachiller-Baeza, B.; Guerrero-Ruíz A.; Rodríguez-Ramos, I. Appl. Catal. A 2006, 300, 120. (c) Jafarian, M.; Moghaddam, R. B.; Mahjani, M.G.; Gobal, F. J. Appl. Electrochem. 2006, 36, 913.

(4) (a) Van Ingen, R. P.; Fastenau, R. H. J.; Mittenmeijer, E. J. J. Appl. Phys. 1994, 76, 1871. (b) Pabi, S. K.; Joardar, J.; Manna, I.; Murty, B. S. Nanostruct. Mater. 1997, 9, 149. (c) Cattaruzza, E.; Battaglin, G.; Polloni, R.; Cesca, T.; Gonella, F.; Mattei, G.; Maurizio, C.; Mazzoldi, P.; D’Acapito, F.; Zontone, F.; Bertoncello, R. Nucl. Instrum. Methods Phys. Res. B 1999, 148, 1007. (d) Damle, C.; Sastry, M. J. Mater. Chem. 2002, 12, 1860. (e) Foyet, A.; Hauser, A.; Schäfer, W. J Solid State Electrochem 2008, 12,47. (f) Bonet, F.; Grugeon S.; Dupont L.; Urbina, R. H.; Guéry C.; Tarascon, J. M. J. Solid State Chem. 2003, 172, 111.

(5) Massalki, T. B.; Okamoto, H.; Subramanian, P. R. Binary Alloy Phase Diagrams, 2nd ed.; ASM International: Metals Park, OH, 1990.

(6) Yin, Y.; Alivisatos, A. P. Nature 2005, 437, 664.

(7) Zhang, Y.; Grass, M. E.; Habas, S. E.; Tao, F.; Zhang, T.; Yang, P.; Somorjai, G. A. J. Phys. Chem. C 2007, 111, 12243.

(8) (a) Ingersoll, J. C.; Mani, N.; Thenmozhiyal, J.C.; Muthaiah, A. J. Power Sources 2007, 173, 450. (b) Kaufman C. M.; Sen B. J. Chem. Soc., Dalton Trans. 1985, 2, 307. 